\title{
MALVINAS: UN ACERCAMIENTO A LAS IMAGÉNES GENERADAS POR COMPUTADORA Y LAS NARRATIVAS TRANSMEDIA
}

\author{
Pablo Francisco Gullino*
}

\section{Introducción}

Desde los primeros años del siglo XXI la consolidación de los medios de comunicación electrónicos produjo un descentramiento con respecto a la primacía de la cultura escrita como factor de transmisión y conservación de la memoria, cobrando fuerte impulso la reflexión y consideración de otras modalidades de construcción. La utilización de diferentes lenguajes y medios potencian las formas de comunicación que promueven cambios cualitativos que complejizan los fenómenos comunicativos en su conjunto. Dentro de este proceso la digitalización de los medios y sistemas de comunicación junto con el desarrollo de las telecomunicaciones introduce un nuevo horizonte sobre el que se proyectan las prácticas comunicativas contemporáneas. En esta coyuntura las técnicas de animación y los cruces transmediáticos (Internet, videojuegos) renacen, tanto en el cine como en la televisión donde las reconstrucciones de ciudades de civilizaciones del pasado, animaciones que recrean batallas históricas o el mundo de los dinosaurios colman de imágenes las pantallas. Los documentales pedagógicos y científicos impulsan esta tendencia (Aprea, 2010). Simultáneamente algunos documentales buscan el

\footnotetext{
* Magister en Diseño Comunicacional - Universidad de Buenos Aires. Licenciado en Comunicación - Universidad Nacional de General Sarmiento. 1665, José C. Paz, Argentina. E-mail: pablogullino@gmail.com
} 
intercambio con las audiencias más allá del momento de la transmisión televisiva al generar otros productos relacionados, en los sitios webs del canal con material exclusivo (videojuegos, textos, audios, etc). Para pensar estos productos nos parece pertinente el concepto de "Post producción" de Nicolás Bourriaud. El término pertenece al mundo de la televisión, el cine y el video; y "designa el conjunto de procesos efectuados sobre un material grabado: el montaje, la inclusión de otras fuentes visuales o sonoras, el subtitulado, las voces en off, los efectos especiales" (Bourriaud, 2009: p. 11). La intervención humana se hace evidente en alteraciones, en la yuxtaposición y combinación de diferentes tipos de imágenes: dibujos realizados a mano inanimados, imágenes generadas por computadora, dramatizaciones, etcétera. En la actualidad, se cuenta con una gran cantidad de técnicas, de efectos de 'iluminación y texturas de superficie. En los programas utilizados en arquitectura es muy común este tipo de tecnología para el procesamiento de la información y su interpretación. Por su parte, los avances en la informática y en la representación de imágenes a partir de simuladores de vuelo han sido utilizados para capacitar a pilotos civiles y militares. Pero también ha tenido un desarrollo comercial en la industria de los videojuegos. Entre estos podemos nombrar al IL-2 Sturmovik, 2001 de Maddox Games, Rise of Flight: The First Great Air War, 2009 de Microsoft, o el clásico Flight Simulator, de Microsoft. Este último fue creado en 1979 y ha sido utilizado incluso con fines profesionales y militares en la capacitación temprana de aspirantes a pilotos. Casi todos los simuladores de vuelo de ámbito militar están ambientados en conflictos aéreos históricos, con aviones realmente existentes. También existen los programas basados en aviones o helicópteros que, aunque reales, pueden ser pilotados en conflictos ficticios (por ejemplo: Falcon 4.0 o Lock On: Modern Air Combat). Además, la afición a los simuladores de vuelo ha hecho que muchos usuarios lleguen a ser diseñadores de aeronaves para estos sistemas. Estas modificaciones del simulador (mods) añaden gran 
valor a la simulación y permiten expandir significativamente la experiencia del vuelo con nuevas situaciones y contenidos. Un caso que podemos citar es el del popular juego Counter Strike tiene un desarrollo sobre Malvinas. En ocasión del $30^{\circ}$ aniversario de la Guerra de Malvinas, la empresa argentina Dattatec creó un espacio en su sitio web en donde los internautas podían dejar mensajes a los soldados que murieron en combate y descargar este desarrollo para el Counter Strike que permite jugar a recuperar las islas, pero en el año 2013. "El CEO de la empresa, Guillermo Tornatore, luego viajó a las Islas y enterró en un pendrive todos esos comentarios en el cementerio Darwin". ${ }^{1}$ Otro ejemplo es el MAJR (Malvinas Argentinas Juego de Recuperación) que desarrolladores argentinos difunden por internet de manera gratuita para usar en PC.

En este sentido, una línea interesante de investigación surge para nosotros a partir de preguntarnos cómo funciona la televisión en relación a proyectos de internet y a las propuestas participativas que el mismo programa genera. Frente a otros momentos históricos nuestra sociedad redefine polémicamente el campo de lo recordable: cambian las perspectivas de selección y conservación y, a su vez, éstas transforman a los objetos convocados. La sociedad modifica sus pedidos al pasado y se redefinen los criterios de validación y jerarquización que definen a lo recordable. Así es que nos encontramos frente a un intento transmediático (que se vehiculiza a través de la televisión, de Internet, de un videojuego y un libro) de proponer una relectura de la Guerra. En este sentido, retomamos el concepto de narrativa transmedia de Carlos Scolari como aquel "tipo de relato en el que la historia se despliega a través de múltiples medios y plataformas de comunicación y en el cual una parte de los consumidores asume un rol activo en ese proceso de expansión" (Scolari, 2013a: 52).

\footnotetext{
1 "Un nuevo mapa del juego Counter Strike permite recuperar las Islas Malvinas" Disponible en: http://www.infobae.com/2013/03/26/702792-un-nuevo-mapa-del-juegocounter-strike-permite-recuperar-las-islas-malvinas
} 


\section{Jet Thunder llega a la televisión}

Jet Thunder: Falklands/Malvinas es un proyecto de videojuego desarrollado por un grupo de entusiastas de la aviación militar. El juego ofrece al jugador la experiencia de participar en la Guerra de Malvinas a partir de un combate aéreo. Los desarrolladores manejaron diferentes fechas estimadas de lanzamiento que, muy a su pesar, nunca lograron concretarse. Como antecedente de este conflicto en particular sólo se cuenta con dos juegos que contaron con apoyo de empresas para llevar a cabo el proyecto y enfocados en los combates aéreos. El primero en ver la luz tempranamente fue Harrier Attack, en 1983 por Durell Software para computadoras Commodore 64. El segundo lanzamiento comercial del juego Dogfight 80 Years Of Aerial Warfare de la empresa MicroProse en 1993.

Jet Thunder es un simulador de vuelo y la guerra de Malvinas ofrece un marco especial. Fue el primer conflicto "moderno", esto es, con la utilización de sistemas de armas avanzados por ambas partes: aeronaves Super Etendard equipadas con misiles Exocet por la Argentina; aviones de despegue y aterrizaje vertical Sea Harrier de Gran Bretaña, entre otros. Se podrá optar por ser parte de alguno de los dos ejércitos enfrentados. Del lado de la Armada Argentina y la Fuerza Aérea Argentina, los aviones disponibles son el Dassault Mirage III, A-4 Skyhawk y para los británicos el jugador puede optar entre pilotear un Harrier o un Aero Vulcan. Debido a que estuvo siendo desarrollado de forma independiente por Thunder Works Studios, sin la participación y apoyo de los productores internacionales, no hubo una fecha precisa para el lanzamiento. Las novedades sobre el desarrollo del producto están en el sitio oficial y en su fanpage de Facebook ${ }^{2}$ Juan Turturro es uno de los integrantes de este proyecto. Al mismo tiempo,

\footnotetext{
${ }^{2}$ Estos son los sitios donde el director César Turturro junto a otros realizadores intentan darle vida al juego sobre Malvinas http://www.thunder-works.com/spanish/noticias.htm https://www.facebook.com/JetThunder?fref=nf
} 
forma parte del estudio Creavisión. A partir de allí el joven creativo utilizó las imágenes generadas para el simulador de vuelo del videojuego en el film 1982; Estuvimos ahí del año 2004 y luego en 1982. La guerra desde el aire. A estas dos obras nos referiremos brevemente a continuación.

\section{Estuvimos ahí - La ficción realista}

El afiche promocional y el tráiler difundido por internet tiene como eslogan la siguiente frase: “Ayer hubo una guerra. Hoy hay héroes”. Es decir, ya desde uno de sus elementos paratextuales más importantes sabemos que el foco de la narración no estará en la guerra en sí como un suceso histórico cerrado, sino como una temática actual centrada en las acciones de dichos héroes. Es un film de bajo presupuesto y de difusión solo por la web o en eventos pequeños en escuelas y salas de cine de la ciudad de Bahía Blanca que relata la historia de dos grupos de militares. Por un lado esta Carlos, un soldado del ejército argentino con 19 años y pocos meses de instrucción militar que aguarda junto a José y Pedro en su trinchera la llegada del enemigo. Por otro lado, un grupo de seis pilotos deben ejecutar una de las misiones más importantes de la aviación argentina; la Operación Invencible. Es decir, atacar y hundir el portaaviones "Invincible", una de las naves más protegidas por las fuerzas armadas británicas. Jean-Marie Schaeffer dice que "un modelo ficcional siempre es de facto una modelización del universo real" (Schaeffer, 2002: 112). Y esta condición se presenta en el film de Turturro al enlazar el destino de sus personajes de ficción al de una misión militar y un enfrentamiento entre las fuerzas terrestres en particular que acontecieron en el mundo histórico.

En los títulos de inicio, el film nos ubica el contexto en el que se da la batalla a partir del 2 de abril de 1982. La iniciativa militar argentina es descripta como un "restablecimiento de la soberanía" después de un periodo de 150 años de “usurpación británica". Entonces, al mismo tiempo que el 
director deja explicita su posición sobre la soberanía argentina en el archipiélago evita analizar las complejas y particulares condiciones políticas que llevaron a la guerra a ambas naciones y sus consecuencias. Decide centrarse en la narración de las acciones militares de los argentinos que efectivamente combatieron y su resistencia frente al invasor europeo. Toda la acción del film va orientada a la aparición de las escenas con imágenes generadas por computadora (CGI). ${ }^{3}$ No son otros que los modelados de las aeronaves pensados en principio para el videojuego Jet Thunder. Vemos desde el comienzo los preparativos de los pilotos y la espera de los soldados en la trinchera a la llegada del invasor. Cuando las escenas de lucha tienen lugar, son las CGI las que dan sentido a la historia de heroísmo en combate. Las escenas de acción hacen uso en muchos casos del sonido de tipo acusmático (Bordwell et al., 1995), crean en efecto un misterio sobre el aspecto de su fuente. También hay en los films de acción, no sólo dentro de los bélicos que ciertos personajes con aura maléfica, importante o impresionante, sean introducidos por el sonido antes de aparecer en cuadro. Esto es lo que podemos observar con los ingleses. Los invasores trastornan la calma aparente de la noche en Monte Longdon y luego lo vuelven a hacer sobre el final del film, cuando un francotirador asesina a Pedro.

Por momentos, son evidentes sus intenciones de alejarse de discursos audiovisuales previos. El grupo de Carlos refugiado en la trinchera a la espera de la llegada de los ingleses, que ya han desembarcado decide tomarse una fotografía. Esta toma de un documento visual adquiere colores sepia, a diferencia del resto de la escena que es a color. La ficción es la imagen en movimiento; la vida de los soldados en las islas, las acciones que los convierten en héroes nacionales. El tono de las imágenes durante la mayor parte del film posee cierto difuminado, otorga una especie de marco

\footnotetext{
${ }^{3}$ Utilizamos este término entre varios posibles, por ejemplo, 3D Computer Animation o Image Synthesis and Computer Animation. El término elegido refiere específicamente al uso del ordenador y al uso de software específico para la creación e imágenes.
} 
de ensoñación. La utilización de actores no profesionales y los tonos saturados con los que el director elije trabajar las escenas de la vida en los pozos de zorro nos recuerdan a los rasgos y el estilo de las secuencias de los documentales televisivos, aquellos registros ficticios (imágenes no documentales) pero imprescindibles para contar la historia. Las escenas previas al enfrentamiento, en las trincheras, son de un ritmo digno de lo real, ya que transmiten a partir de recursos como la monotonía y los silencios.

Sobre las características de los personajes, nos parece importante rescatar los aportes de la historiadora norteamericana Jeanine Basinger (citada en Revuelta Rojo, 2008: 30) sobre los films de guerra donde se suele presentar el siguiente esquema de personajes característicos:

a) El Héroe: todo filme bélico cuenta con uno o varios personajes que destacan del resto por su heroísmo. Suele encarnarse en un oficial competente y heroico. Muchas veces es un militar de carrera que guía al grupo de conscriptos en el campo de batalla. Para este film, el héroe está en la piel del piloto sobreviviente del ataque

b) Grupo de soldados de distinta procedencia: Los soldados pertenecen también a distintos grupos socioeconómicos y etnias. Por ejemplo, el estudiante universitario (el soldado Webster de Hermanos de Sangre (Spielberg, 2001) un granjero, un afroamericano, etc. Esto encontramos en 1982: Estuvimos Ahí. Los diálogos en las trincheras son de soberanía del territorio, de orígenes arraigados con fuerza ("Mis abuelos eran aborígenes. También tuvieron que pelear para defender su tierra. Como nosotros, ahora."). También se le otorga un importante rol a la religión y a la simbología cristiana. En una escena muy emotiva uno de los soldados le regala al momento de morir a su compañero un rosario. $\mathrm{Y}$ le dice: "La fe me ayuda mucho. Tenés que rezar. Aunque no creas mucho o te parezca una boludez". Ese objeto, el rosario, está al comienzo del film cuando el soldado en tiempo presente recuerda los sucesos de la guerra y vuelve a aparecer al final. Con el soldado que recuerda de regreso a las Islas. En el Cementerio 
de Darwin lo vemos dejar sobre una de las tumbas el rosario. En este sentido, Jean- Marie Schaeffer (2002) afirma que la identificación del estatus (ficción versus documental) de una película casi nunca plantea problemas, debido a que la separación entre el nivel de la inmersión y el de las creencias es fundamental. Sin embargo, los casos mixtos son preponderantes. Esta película maneja estos dos niveles y a partir de ello genera un tipo de relato complejo con una retórica de simulación documental. Un movimiento pendular constante entre personajes ficcionales envueltos en fechas y ubicaciones históricas.

1982: Estuvimos ahí también recupera algo de ese Hollywood que construye épicas sobre reveses militares. A partir de la derrota en la guerra, se cuenta una historia de valor y coraje comienza con una placa en fondo negro y letras blancas que nos advierte sobre la ficcionalidad de los hechos y personajes presentados a continuación. Pero, al mismo tiempo, a continuación de esa información inicial le siguen unas placas informativas sobre la Guerra de Malvinas que hacen referencias a lugares, nombres propios (personas, barcos, aviones) existentes. Sobre el cierre de este texto introductorio, se nos notifica que la historia que se va a contar transcurre en Goose Green (Pradera del Ganso), el 27 de mayo de 1982. Es decir, una batalla real. Es aquí donde comienza la construcción del verosímil que propone el director. Al igual que otros films de tipo bélico televisivos y cinematográficos se introduce al espectador en la temática general mediante un cúmulo de índices didascálicos, según la clasificación canónica de Casetti y Di Chio (1991). ${ }^{4}$ A continuación, vemos a uno de nuestros personajes sentados en un café. Los subtítulos nos ubican de manera temporal y geográfica: "Bahía blanca, Argentina. Época actual”. Es este

\footnotetext{
4 "Estos códigos regulan la materia de la expresión que va a constituir, junto con la imagen gráfica en movimiento, el componente visual del cine: hablamos de indicios gráficos, es decir, de todos los géneros de escritura que están presentes en un film. Para poner un poco de orden, podemos subdividir los indicios gráficos en: didascálicos, subtítulos, títulos y textos". (Casetti, Di Chio, 1991: 96).
} 
personaje quien empieza a recordar la Guerra. Ahí es donde el espectador se da cuenta que está frente a un veterano de Malvinas. Mediante imágenes que actúan a manera de recuerdos, de rememoración del protagonista. Incluso con sus limitaciones, 1982: Estuvimos Ahí intenta construir credibilidad a partir de la utilización del idioma como índice de lo real; el personaje inglés solo habla su lengua nativa y el film hace uso de subtítulos para traducir sus escasísimas líneas. Otro momento que contribuye a la construcción de la estructura del film son las secuencias a color, similares a los rasgos y el estilo relacionados con la dramatización de los documentales.

\section{Malvinas, la guerra desde el aire - imágenes nunca vistas}

1982. Malvinas, la guerra desde el aire, de César Turturro, transmitido durante el año 2009 por la señal de televisión History Channel. Este documental propone trabajar sobre un aspecto supuestamente inédito en las narraciones audiovisuales sobre Malvinas: el papel exitoso que cumplió la Fuerza Aérea Argentina a lo largo del conflicto. El recurso visual fundamental para sus realizadores es la presentación de "imágenes únicas" generadas por computadora. Estas imágenes "realistas y exactas" 5 recrean los combates aéreos y el hundimiento de flotas británicas. En 1982GDA varias secuencias se repiten para explicar hechos diferentes. ${ }^{6} \mathrm{Al}$ correr el velo de la artificialidad de la construcción mediática, el director puede tomarse esta licencia y repetir una escena hasta, incluso, cuatro veces. El autor del documental exhibe con el registro de algunos testimonios los

\footnotetext{
${ }^{5}$ La gacetilla de prensa del documental promete: "Imágenes únicas que recrean los momentos históricos que hasta el día de hoy no han sido vistas por nadie más que los protagonistas de cada uno de los combates. A través de reconstrucciones en animaciones CGI, realistas y exactas, bajo el detallado relato de los propios pilotos, se desarrolla este programa de la última batalla de la guerra fría y el bautismo de fuego para la Fuerza Aérea Argentina." Disponible en: http://www.0291.com.ar/articulo/4783/URI

${ }^{6}$ El ataque al Sheffield y 1 Atlantic Conveyor tiene las mismas animaciones, pese a ser hechos de días diferentes.
} 
aviones reales, dando cuenta de la similitud entre el objeto real y la representación construida con un programa de diseño. ${ }^{7}$ Aquí se dan algunas críticas a mandos superiores sobre el armamento con el que se contaba. Los aviones de la Armada no estaban preparados para este tipo de operaciones. Ahora el héroe, en términos de Jeanine Basinger, está encarnado en la Fuerza Aérea Argentina. Por sus técnicos quienes trabajan contra reloj para poner a punto el material bélico. En este caso, no hay un relato sobre las condiciones climáticas adversas ni denuncias sobre el trato que recibían los conscriptos como sí sucede en otros relatos audiovisuales argentinos del periodo. Y este es un quiebre fundamental con los documentales argentinos que abordaban la Guerra de Malvinas hasta los comienzos del siglo XXI. Aquí el oponente es, claramente, el ejército británico. Pero también las limitaciones del material bélico, inferior al usado por los ingleses. De hecho, el relato gira alrededor de este concepto. Pese a la inferioridad numérica y tecnológica, la Fuerza Aérea logró resistir y atacar incluso hasta en momentos posteriores a la capitulación argentina.

Sobre los testimonios, es llamativa la nominación de los entrevistados. A diferencia de piezas documentales precedentes al periodo analizado, no se habla de ellos como veteranos de guerra o ex combatientes. Se los llama "pilotos". Son ellos mismos quienes describen detallada y minuciosamente los riesgos de volar a menos de diez metros del mar y a una velocidad de mil kilómetros por hora, los bombardeos, los enfrentamientos aire-aire y las dramáticas recargas de combustible en medio del océano. Este relato vivencial se articula a partir de la experiencia directa de sus protagonistas. Es esta intención del director está fuertemente marcada.

\footnotetext{
7 "Fue una vorágine porque empezamos a contactar a los pilotos, armar el guión, y trabajar las animaciones porque los tiempos de 3D son enormes, lo que se ve en diez segundos puede llevar un trabajo de dos meses, es un trabajo muy puntilloso, porque hay que generar todo: la luz, el agua, las condiciones climáticas. En enero ya estábamos grabando las notas en Buenos Aires con los pilotos, e hicimos filmaciones acá en Espora". Entrevista al director del documental, César Turturro.

Disponible en: http://www.ecodias.com.ar/art/1982-malvinas-la-guerra-desde-el-aire
} 
Todos los entrevistados son integrantes de la Fuerza Aérea que combatieron en 1982.

Al acotar el acontecimiento de la guerra a los combates librados por la Fuerza Aérea, parece acercarse a las costas de cierto planteo de la historia contrafactual. Sobre los últimos 5 minutos del documental, momento de conclusiones, uno de los entrevistados afirma que: "Si uno hace números, la guerra económica la ganó la Fuerza Aérea Argentina. Porque los A4 eran aviones viejos que nadie calculó que iban a dañar a una flota tan profesional y moderna". Al mismo tiempo, el relator asegura que: "El conflicto deja a los británicos con su flota desmantelada. Y no es posible proseguir con las batallas navales". Las dificultades de los pilotos en el uso de sus aviones en combate son detalladas por los testimonios de sus protagonistas. Sin embargo, no se explican las causas de las ausencias de asientos eyectores, combustible y otros elementos vitales para el combate aéreo y que perjudicaron - al punto de producir varias bajas- a los argentinos.

\section{A modo de cierre}

En los dos films analizados las CGI nos ubican frente a una base de la estructura del discurso y la estética diferente a la los años posteriores al final inmediato del conflicto. Las narraciones de Malvinas se anclan en el testimonio de batallas específicas y la experiencia de quienes efectivamente participaron de los combates. Las CGI ilustran las imágenes de estas escenas de acción bélica y en muchos casos son el argumento fundamental para promover su visualización, la posibilidad de ver imágenes "nuevas". La animación construye referentes visuales a hechos y personajes del pasado reciente, con una dimensión simbólica que el registro de base fotográfica no podría aportar. Las CGI se anotan en este juego desde la cultura visual mediática contemporánea para recuperar las posibilidades que ofrece la tecnología y la imaginación de los realizadores para producir piezas 
audiovisuales que implican nuevas formas de contar el pasado. A futuro, nos interesa explorar como es que se expanden estas narrativas audiovisuales de las que nos notifica Carlos Scolari (Scolari, 2013b), pero en relación a la historia y la memoria. En las distintas formas de dar sentido a la experiencia de lo vivido y de incorporar imágenes de combates aeronavales producto del desarrollo de las tecnologías informáticas.

\section{Referências bibliográficas}

APREA, Gustavo (2010), "La construcción del conocimiento en los documentales: entre la indicialidad y la digitalización” en Gabriel Yoel y Alejandra Figliola (Coord.) Bordes y texturas. Reflexiones sobre el número y la imagen, Buenos Aires: Imago Mundi., pp. 153162

APREA, Gustavo (comp.) (2012), Filmar la memoria. Los documentales audiovisuales y la re - construcción del pasado, Los Polvorines: Imago Mundi - UNGS.

BORDWELL, David; THOMPSON, Kristin (1995), El arte cinematográfico: una introducción. Barcelona: Paidós.

BOURRIAUD, Nicolas (2009), Postproducción: la cultura como escenario. Modos en que el arte reprograma el mundo contemporáneo. Buenos Aires: Adriana Hidalgo.

CASETTI, Francesco, DI CHIO, Federico (1991), Cómo analizar un film, Barcelona: Paidós.

FIGLIOLA Alejandra (2010), "Notas al pie para Image Future" en Gabriel Yoel y Alejandra Figliola (Coord) Bordes y texturas. Reflexiones sobre el número y la imagen, Buenos Aires: Imago Mundi., pp. $197-$ 202 
REVUELTA ROJO, Elisa (2008), "Evolución del cine de ficción sobre la

II Guerra Mundial: el caso del Desembarco de Normandía" en Revista de la SEECI, n. 16. Julio. Año XI.

Disponible en:

http://www.seeci.net/revista/index.php/seeci/article/view/175.

SCHAEFFER, Jean-Marie (2002), Por qué la ficción Madrid: Lengua de Trapo.

SCOLARI, Carlos (2013a), Narrativas transmedia: cuando todos los medios cuentan, Barcelona: Deusto.

SCOLARI, Carlos A. (ed.) (2013b), Homo Videoludens 2.0. De Pacman a la gamification, Barcelona: Universitat de Barcelona.

\section{Filmografía}

1982, Estuvimos ahí (Argentina, 2004), de César Turturro y Fernando Acuña

1982 Malvinas La guerra desde el aire (Argentina, 2009), de César Turturro (Escritor: Jorge Luis Sucksdorf) 